\title{
O Nordeste e a História Oral: a contribuição dos Grupos de Pesquisa do Ceará*
}

\author{
Gisafran Nazareno Mota Jucá**
}

O objetivo deste artigo é apresentar um levantamento que nos leve a refletir sobre as experiências metodológicas realizadas, no Ceará, no campo da oralidade, a fim de que possamos divisar os avanços e recuos das práticas de pesquisa voltadas a essa nova opção metodológica.

Para uma melhor compreensão do avanço das pesquisas no campo da história oral, selecionamos quatro grupos de pesquisa, instalados em duas de nossas universidades: a Federal, (UFC) e a Estadual (UECE).

\section{1}

$\mathrm{Na}$ UFC, como resultado do interesse do Reitor Prof. Paulo Elpídio de Menezes Neto, que desde o início de sua gestão almejava implantar um Centro de Referência Cultural, em junho de 1983 foi instalado o Núcleo de Documentação Cultural - NUDOC - que contou com o empenho pessoal da Professora Dra. Tereza Frota Haguette, do Departamento de Ciências Sociais, indicada pelo reitor para organizar o referido Núcleo. ${ }^{1}$

* Este artigo diz respeito a minha participação, como palestrante, da Mesa Redonda "A História Oral no Nordeste", no V Encontro de História Oral do Nordeste, realizado no período de 5 a 9 de setembro de 2005, em São Luís do Maranhão.

** Professor do Curso de História da Universidade Estadual do Ceará (UECE). Líder do grupo Oralidade, Cultura e Sociedade, da UECE.

1 O referido Reitor, desde quando ocupava a função de Pró-Reitor de Pesquisa e Pós-Graduação, em 1979, além de incentivar a criação do Núcleo de Estudos Sociais - NEPS - sugeriu a criação de um Centro de Referência Cultural, idéia concretizada com a instalação do NUDOC. 
A nosso ver, o modelo adotado pelos seus pesquisadores teve como padrão orientador a experiência das pesquisas desenvolvidas pelo CPDOC, no Rio de Janeiro - inclusive, em 1981, a Professora Aspásia Camargo ministrou, no Departamento de Ciências Sociais da UFC, um Curso de História Oral, para aperfeiçoamento dos pesquisadores do NUDOC.

O primeiro projeto, elaborado pela Professora Teresa Haguette, intitulava-se História do Ceará: Políticas, Indústria e Trabalho, e contou com o apoio da FINEP, no período 1984-1991. Outras pesquisas foram apoiadas pelo CNPq, na década de 1980. Além dos Convênios, no período 1986-1990 foram lançados 17 números das publicações do Projeto História do Ceará - Série Idéias. Em 1989 foi lançada a Coleção Estudos Históricos, num total de seis livros: sobre a Estrada de Ferro de Baturité, a indústria, o trabalho industrial, eleições e movimento dos trabalhadores rurais no Ceará. Alguns desses livros eram dissertações do Mestrado em Ciências Sociais, orientadas pelos professores André e Teresa Haguette e nem todos eles tiveram por opção metodológica o emprego da história oral.

$\mathrm{Na}$ Série História foram lançados onze números dos cadernos do NUDOC, contando inclusive com a participação de professores do Curso de História. Entretanto, os depoimentos transcritos do Programa de História Oral resultaram num total de 44 trabalhos sobre lideranças políticas, sindicais, comunitárias e industriais. Na parte relacionada a projetos específicos, os estudos foram dedicados à história da UFC, história política do Ceará, história da pintura no Ceará e história da pastoral operária no Ceará.

Vale salientar que, no período de sua fundação, o Curso de História ainda não tinha autonomia administrativa, sendo o seu corpo docente vinculado ao Departamento de Ciências Sociais e Filosofia. O curioso é que nenhum dos professores da história fez parte do NUDOC na sua fase inicial. Embora o NUDOC tivesse sido implantado através de uma proposta interdisciplinar, com o objetivo de congregar pesquisadores das áreas de Ciência Política, Sociologia, Filosofia, Letras e História, na verdade houve um certo confronto entre os dirigentes do NUDOC e os professores da área de história. Para que se possa ter uma visão da relação entre os membros do NUDOC e os docentes de história, vale atentar para o seguinte comentário:

Segundo o anteprojeto de Regimento Interno elaborado na primeira gestão (1983 - início de 1987) a coordenação do NUDOC 
estava aberta a qualquer profissional das áreas das Ciências Sociais e História, que representavam os dois cursos mais diretamente vinculados a sua área de atuação. Entretanto, na segunda gestão, [1989] o Regimento foi modificado limitando a coordenação do NUDOC somente a professores de História, o que pareceu um retrocesso corporativista. Na verdade, este desfecho já era esperado uma vez que os docentes de História - com algumas exceções - nunca aceitaram que um sociólogo pudesse coordenar um núcleo de memória oral que, a seu ver, deveria ser monopólio dos historiadores. Este repúdio se consubstanciou na recusa de participação dos professores de História em qualquer atividade promovida pelo NUDOC apesar dos veementes convites feitos pela coordenação durante a gestão Haguette, conforme documentos probatórios. (Menezes, 1991, p. 190-191)

Sobre a não participação de professores de História na fase inicial do NUDOC, a sua atual Coordenadora, a professora Adelaide Gonçalves Pereira apresenta uma outra versão: "Isso sem dúvida configura problemas institucionais, eu entendo que muito mais do que diferenças no campo conceitual". E acrescenta a seguinte indagação: “Terá sido o NUDOC, criado por uma exigência acadêmica ou terá sido ele criado por um a exigência institucional?" (Entrevista realizada em 17/6/2006). Na verdade, o NUDOC partiu de uma proposta da Reitoria da UFC, que almejava obter recursos de órgãos financiadores para viabilizar o desenvolvimento de pesquisas na área de Ciências Sociais e não exclusivamente da idéia de recorrer à interdisciplinaridade como inovação metodológica.

Para uma melhor reflexão acerca das propostas apresentadas pelos pesquisadores do NUDOC e os resultados obtidos no seu cotidiano, observe-se o destaque apresentado pela professora Adelaide:

O NUDOC é importante para a pesquisa na UFC, na área de ciências humanas, desde a sua criação. Eu acho que há que se fazer justiça aos sujeitos envolvidos nesse processo de vinte anos. Pode-se fazer crítica de abordagem, crítica de aparato conceitual ou da própria formação das equipes de pesquisadores, não estou falando da formação acadêmica, estou falando portanto da ausência de interdisciplinaridade, mas é importante a criação do 
núcleo porque começamos a ter de modo institucional o desenvolvimento de pesquisas e as mais publicações eventuais, a depender das amizades internas que se possa ter na Instituição e da ausência de projetos editoriais.

Sobre a decisão em manter a coordenação do NUDOC restrita a um profissional da história, a professora Adelaide afirma:

O caso do NUDOC especificamente é compreensível à luz das disputas institucionais ou das disputas internas, as unidades acadêmicas que o regimento do NUDOC tenha portanto estabelecido que a sua direção acadêmica ficasse restrita à área de história. Isso é compreensível do ponto de vista interno, se fôssemos pesquisar desde o começo da história do NUDOC. No entanto, eu penso que à luz da prática de pesquisa este não é um bom princípio. Acho que o princípio mais adequado é o princípio pois da discussão da interdisciplinaridade.

Na verdade, a chamada segunda gestão do NUDOC, confiada ao professor Eurípedes Antonio Funes, diz respeito exatamente ao período em que o NUDOC passou a fazer parte do Curso de História. Para tanto, segundo depoimento do professor Haguette, o apoio do Diretor do Centro de Humanidades foi decisivo para a concretização do desejo dos professores do Curso de História.

A partir desse período, com o patrocínio do Banco do Nordeste do Brasil, foi realizado um estudo sobre "história política constituinte da região nordeste" e também publicado o Roteiro sentimental de Fortaleza. Segundo a professora Adelaide, "essa publicação é uma publicação realizada já há cinco anos, reunindo memórias de importantes intelectuais, a exemplo deles destaco Moreira Campos e o trabalho de transcriação, realizado ali, é um trabalho da melhor qualidade, do ponto de vista metodológico”. Também foram realizadas entrevistas com membros da Federação das Indústrias do Ceará, inclusive empresários da “[...] proclamada geração mudanças no Ceará e desse novo signo político no Ceará” (Idem), além da história e memória da Imprensa e do Jornalismo no Ceará.

Quanto ao intercâmbio do NUDOC com outras Instituições de Pesquisa, iniciado com o apoio recebido do CPDOC, merece destaque a 
participação do Prof. José Carlos Sebe Bom Meihy, da USP, autor de alguns prefácios das publicações lançadas em Fortaleza.

\section{2}

Ainda na UFC, em 2003 foi constituído o Laboratório de Estudos da Oralidade, com uma perspectiva interdisciplinar, reunindo um grupo de professores da Pós-Graduação em Ciências Sociais, das áreas de Antropologia, Literatura e Comunicação Social e também da área de Música da UECE. Todos desenvolvem pesquisas no campo da oralidade e da textualidade e têm apresentado produção nesta área de trabalho. O grupo conta também com a participação de alunos e se apresenta como um espaço para a realização de seminários com o objetivo de formar pesquisadores, além de apresentar uma proposta de publicações, registros de CDs e de outros recursos audiovisuais. O banco de dados a ser instalado pretende fornecer subsídios não apenas ao meio universitário, mas à própria sociedade, com o intuito de apoiar políticas públicas, oriundas tanto da ação governamental quanto de organizações não-governamentais.

O Departamento de Ciências Sociais da UFC cedeu ao Laboratório de Estudos da Oralidade uma sala, onde foi instalada uma biblioteca dispondo de 1.800 volumes doados pelos professores envolvidos no projeto, cujos temas são voltados às áreas de Antropologia, Religiões Afro-Brasileiras, História, Literatura, com destaque no cordel, Comunicação, que destaca o comunitário e o alternativo e a Musica, envolvendo aboio e cantoria do interior cearense.

\section{3}

Na Pós-Graduação em Educação, na Universidade Federal do Ceará, o interesse pela história oral se intensificou quando da implantação do Doutorado, em 1995. A Professora Maria Juraci Maia Cavalcante, ao retornar do Doutorado, dedicando-se ao estudo da grade curricular, sentiu falta de uma literatura sobre história educacional do Ceará. Como ponto de partida de pesquisa sobre essa temática, com o apoio de um grupo de vinte alunos, iniciou o levantamento sobre 50 anos de manchetes, nos jornais, relativas à política educacional. Segundo a Professora Juraci: 
Então, assim, eu entrei no Núcleo de Política Educacional, que já existia e inseri a história educacional, que hoje se chama memória, história e política educacional. Por que memória? Porque a gente não queria só a história baseada em documentos, história institucional, a história das políticas, mas da vida privada, do cotidiano das escolas, das práticas efetivas dos professores... (Entrevista com a professora Maria Juraci Maia Cavalcante, 21/6/2004).

Além do interesse em história educacional, centrada em fontes documentais, havia a proposta de "[...] um projeto de memória de velhos analfabetos, memória de migrantes, memória de educadores, também projetos biográficos, autobiográficos, projetos que envolvem histórias de vida, que passam muito pelo campo da história oral" (Idem). Com o apoio do professor José Gerardo Vasconcelos e como resultado de reuniões semanais do núcleo, foram programados encontros anuais, no período 2001 a 2005, e, além da organização dos Anais, os trabalhos apresentados passaram a ser publicados em uma coletânea intitulada Coleção Diálogos Intempestivos (Magalhães Junior, 2001; Cavalcante, 2002; Cavalcante e Bezerra, 2003).

Provavelmente um fator positivo para o avanço das atividades, nesse grupo de pesquisa, seja a área interdisciplinar da Pós-Graduação em Educação. Na verdade, seus membros possuem formação diversa: Letras, História, Ciências Sociais, Psicologia, Serviço Social, o que torna estimulante a troca de experiências e abordagens, de acordo com as propostas apresentadas.

\section{4}

Na UECE, a partir de 2002 foi implantado, no Mestrado de Políticas Públicas e Sociedade, o Grupo de Pesquisa intitulado Oralidade, Cultura e Sociedade, sob nossa coordenação, que estabeleceu como meta propiciar a troca de experiências nas diferentes áreas das Ciências Humanas e Sociais. Os seus componentes, partindo do alcance da interdisciplinaridade, dedicaram-se a uma linha de pesquisa direcionada à investigação das "distinções e do contínuo rural-urbano", na perspectiva da Cultura, da Linguagem, da Comunicação e do Patrimônio. Desse modo, o trabalho desenvolvido entre os pesquisadores constituía uma busca de uma nova 
abordagem na investigação dos fenômenos culturais, recorrendo a critérios metodológicos de novas vertentes sobre estudos da oralidade.

Como ponto de partida das pesquisas foi estabelecida a temática "Caminhos e Descaminhos da Oralidade na Cultura Regional" como indicativo que propiciasse a troca de experiências nas diferentes áreas das Ciências Humanas e Sociais. No roteiro das propostas apresentadas, integraram a referida linha temática os seguintes projetos:

- A Rota da Rede Viação Cearense na Simbologia da Narrativa Popular, de minha autoria.

- Por uma Estética da Cultura da Tradição Oral: o aboio na sua relação com o cancioneiro do Ceará, de autoria da Profa. Dra. Elba Braga Ramalho, do departamento de Artes da UECE.

- Mãos Silenciosas Modelando Areias, de autoria da Profa. Dra. Maria Esther Barbosa Dias, do Departamento de Serviço Social da UECE.

Além desses três iniciadores do GP, contamos com o apoio de professores das áreas de Educação, História, Serviço Social, incluindo alunos do Mestrado em Políticas Públicas e também alunos da graduação. A princípio, selecionamos textos de apoio, desde os livros dedicados à metodologia (Meihy, 2000; Caldas, 1999; Freitas, 2002) àqueles que propiciaram subsídios teóricos e serviram de apoio aos passos iniciais na nova opção metodológica (revista História Oral e o número especial de Projeto História, além de Ferreira e Amado, 1998, e Bosi, 2003).

Além de três livros publicados - dois deles escritos pela professora Elba Braga Ramalho, relativos à sua dissertação de Mestrado e à tese de Doutorado, e um de nossa autoria, referente à tese para concurso de professor titular -, foi publicado um número especial de O Público e o Privado (n. 2, jul.-dez./2003), cadernos dos Núcleos e Grupos de Pesquisa vinculados ao Mestrado Acadêmico em Políticas Públicas e Sociedade da UECE, cuja apresentação foi feita pelo Prof. Antonio Torres Montenegro. ${ }^{2}$

Os nossos seminários foram programados uma vez por mês, a fim de possibilitar aos participantes a leitura antecipada do texto ou livro selecionado. A busca da compreensão das fronteiras e dos liames entre

2 Um total de treze artigos, cujos autores são professores e alguns alunos, bolsistas de iniciação científica e alunos do Mestrado, envolvendo diferentes temas, desde as questões metodológicas a outras abordagens, como educação, música, artesanato, ferrovia, memória popular e questão indígena. Ramalho, 2000a e 2000b; Jucá, 2003. 
memória, história e Narração, revelou-nos o valor da fundamentação teórica no arcabouço da construção do tear da oralidade. ${ }^{3}$

A experiência profissional vivenciada pela colega Elba Braga Ramalho, que cursou o seu doutorado no Departamento de Música da Universidade de Liverpool, nos remeteu a outras leituras, que nos fizeram compreender algo mais do que os estreitos limites da história oral, pois nos revelou a riqueza e a dinâmica da oralidade no campo das demais ciências humanas (Ramalho, 2000b). Nessa trilha, três autores, além do campo da história, nos revelam novas dimensões da tradição oral: Eric Havelock (1996), Paul Zumthor (1993) e Walter Ong (1998).

O primeiro procura apresentar uma imagem de uma crise que ocorreu na história da comunicação humana, quando a oralidade grega se transformou em literatura. Zumthor oferece um paradigma que nos revela a voz e a performance entre os elementos constitutivos da obra literária. Walter Ong, além das diferenças entre oralidade e cultura escrita, destaca a supervalorização atribuída à escrita, esquecendo que ela nasceu na oralidade e ainda mantém uma íntima relação com a mesma. Apesar do avanço da tecnologia eletrônica, é bom não esquecermos a presença de um forte resíduo oral na literatura.

Uma vez que as reuniões do nosso GP Oralidade, Cultura e Sociedade foram programadas para ocorrer mensalmente, além das questões metodológicas, a preocupação central, nos encontros realizados, voltou-se à fundamentação teórica. E como trilha inicial, na busca de um maior aporte teórico, além de Walter Benjamin e Pierre Nora, outro autor que se tornou fundamental a suprir nossa carência foi Paul Ricouer. Como é do conhecimento geral, há diversos trabalhos destacando a contribuição deste autor na renovação conceitual das ciências sociais: sejam entrevistas, ensaios ou mesmo teses, como a do Professor de Filosofia, Ivanhoé Albuquerque Leal (Cf. Ricoeur, 1998 e 2002; Leal, 2002).

Entretanto, foi através da contribuição de um historiador, que conseguimos compreender melhor a dimensão da abordagem de Ricoeur nesse avanço teórico-metodológico da história. Refiro-me aos ensaios, publicados em capítulos dos livros de François Dosse (Cf. Dosse, 2001, 2003a; 2003b). Se compararmos esses trabalhos, a princípio podem parecer repetitivos, mas uma leitura atenta dos mesmos nos faz perceber o

3 Além de Kothe, 1985; Rouanet, 1985; Gagnebin, 1999 e Nora, 1993. 
significado de cada um deles, pois nos fornecem argumentos que nos levam a repensar os estreitos limites implantados na nossa tradição teórico-metodológica.

Conforme nos lembra Dosse, se fizermos uma retrospectiva acerca do avanço no campo das ciências sociais, o curioso é a distância que foi mantida entre os profissionais da história e da filosofia durante muito tempo. E essa necessária aproximação permaneceu impossível, inclusive na própria França, onde a história conseguiu adentrar no campo das ciências sociais. Enquanto os pesquisadores da Nova História buscavam apoio nos diálogos mantidos com áreas afins, a contribuição de Ricoeur se apresenta como preciosa, ao definir tempo o histórico como um conceito ao qual o historiador deve se apegar para melhor compreender a sua prática disciplinar. A sua contribuição representa um novo instante do avanço historiográfico, inclusive nos fazendo repensar alguns conceitos apresentados pela nova história.

Um dos traços marcantes do avanço do pensamento histórico quase sempre foi uma ruptura radical com correntes anteriores, insistindo-se na descoberta de uma nova opção, capaz de superar as visões consideradas inferiores às do tempo presente. E Ricoeur não procura romper com o passado, mas busca nele o apoio necessário para a abertura de novas trilhas. Ele sempre deixou claro que a riqueza do trabalho do pesquisador em história depende de se levar em conta não apenas o conteúdo escolhido, mas as condições em que esse conteúdo foi elaborado, destacando a relação entre o explicar e o compreender, entre a subjetividade e a objetividade, redefinindo o alcance da narrativa.

Embora desde os anos 1950 Ricoeur se debruçasse sobre a história, não era considerado importante, pois nessa época ainda vigorava um certo objetivismo, mesmo se propalando o contrário, com a arrancada do estruturalismo, que influenciou de forma marcante o conhecimento histórico, pois se dava muito destaque a pressupostos cada vez mais rígidos, o que tornava o panorama pouco propício às teses de Ricoeur sobre a ação histórica. Com o desmoronamento dos grandes modelos, marxismo e estruturalismo, e a mudança interpretativa, que daí resultou, o valor da contribuição desse pensador torna-se mais evidente na busca de novas explicações históricas.

A publicação dos três volumes de Tempo e Narrativa ocorreu no período 1983 a 1985. O primeiro pensador a discutir a importância da 
contribuição de Ricoeur para a história foi Michel Certeau e, entre os historiadores, Roger Chartier, que passou a considerar Tempo e Narrativa como uma das principais publicações sobre história dos anos 1980. Para Chartier, a principal contribuição de Ricoeur foi romper com a tradição dos historiadores franceses que recusavam a aproximação da filosofia com a história. Apesar da história procurar distanciar-se da ficção, ela não consegue romper com a narrativa, como acreditavam os seguidores dos Annales, a fim de construir algo que sobrepujasse a narrativa. Na verdade, embora a história seja narrativa, não se trata de um tipo qualquer de narrativa. Por isso, Ricoeur distingue história e literatura, pois a primeira não pode fugir ao que realmente aconteceu (Cf. Dosse, 2001).

Para Ricoeur, a história depende de uma relação entre objetividade e subjetividade, explicação e compreensão. O trabalho do historiador é revelar que a prática de sua atividade representa uma tensão constante entre uma objetividade incompleta e a subjetividade, que não se prende a uma total ruptura com a realidade analisada, apesar de ela persistir ao longo de todo o trabalho elaborado, passando a ser a intermediária necessária para que se possa ter acesso à objetividade.

A leitura de um passado histórico já não mais se prende à busca de um simples acontecimento, mas nos remete a um processo mais amplo, onde vários são os temas e os agentes nele envolvidos. Na quebra da visão fechada sobre o conceito de fato histórico, o significado da narrativa torna-se mais revelador, abrindo novos horizontes para a reconstrução das experiências históricas. E o principal resultado para a história, ao reconhecer o alcance da narrativa, é poder superar os estreitos limites da definição de cientificidade, que lhe eram impostos, abrindo perspectivas de abordagens mais significativas, partindo da compreensão da história através de uma sucessão de ações, pensamentos e sentimentos, os temas estudados apresentam ao mesmo tempo revelações e surpresas. O estudo dos textos e da ação humana nos conduz a uma ação reveladora das ações da experiência humana no passado.

$\star \star \star$

Ao fazer uma análise acerca das experiências dos quatro grupos de pesquisa dedicados à oralidade que atuam no Ceará, observamos que a transdisciplinaridade, ou mesmo a decantada interdisciplinaridade, apesar 
de reconhecidas como suporte básico à produção do conhecimento, ainda enfrentam alguns obstáculos. Veja-se, por exemplo, o avanço das pesquisas registrado no NUDOC e a seguinte indagação, apresentada pela professora Adelaide:

Nessa segunda fase, em que o NUDOC localiza-se institucionalmente no Departamento de História, terá sido praticada a interdisciplinaridade como premissa do conhecimento, da ação da pesquisa?... Não vou responder essas perguntas, mas isso deve ser indagado a partir das pesquisas, a partir das pessoas que passaram a ser pesquisadoras do NUDOC!

O Grupo de Pesquisa da Pós-Graduação em Educação tem conseguido um avanço na sua experiência, basta que se considere o número de dissertações e teses que se apoiaram na metodologia da oralidade. No nosso entender, essa facilidade de intercâmbio propiciado por esse GP resulta da originalidade da sua própria constituição. A sua primeira coordenadora é uma pesquisadora oriunda das Ciências Sociais e alguns de seus membros são formados em História, Educação, Biblioteconomia e Ciências Sociais.

A própria experiência do nosso grupo Oralidade, Cultura e Sociedade tem propiciado a aproximação entre pesquisadores de História, de Artes, das Ciências Sociais, do Serviço Social e da Pedagogia, e como nossos encontros são direcionados à discussão dos textos teórico-metodológicos, apesar dos projetos ainda permanecerem individualizados, o reconhecimento da transdisciplinaridade como suporte ao avanço do espírito crítico tem um significado especial, servindo de estímulo contínuo à superação das tradicionais barreiras.

Quanto ao Laboratório de Estudos da Oralidade, ligado à Pós-Graduação em Ciências Sociais, parece-nos mais voltado ao intercâmbio com grupos de pesquisa de universidades estrangeiras, principalmente da França, não manifestando interesse em trocar experiências com os grupos de pesquisa existentes nas nossas duas universidades.

Considerando as práticas dos GPs voltados à oralidade, no Ceará, além do avanço no número de trabalhos publicados - veja-se, como exemplo, as duas fases de trabalhos do NUDOC - é necessário insistir na busca de um maior embasamento teórico, como se verifica na experiência 
de nosso grupo, seguindo a trilha aberta por Paul Ricoeur e na aceitação de pesquisadores provenientes de diferentes áreas das ciências humanas, conforme se observa no GP da Pós-Graduação em Educação.

De qualquer modo, os primeiros passos já foram dados, mas ainda existem muitos entraves para concretização da almejada aproximação entre os pesquisadores das ciências sociais. Afinal, além de tentar superar os estreitos limites de uma história oral, mais voltada à aplicação de técnicas dinâmicas, é preciso reconhecer e difundir a descoberta da oralidade, que nos remete além das fronteiras tradicionais de uma mecânica história oral. Como enfatiza Dosse, é bom também não esquecer que "a transdisciplinaridade tem como vantagem [...] o fato de sair da rotinização e das falsas garantias com que se enfeitam as disciplinas. De fato, ela permite problematizar objetos constituídos como obstáculos por uma ou outra disciplina como obstáculo por causa dos seus limites intrínsecos” (Dosse, 2003b, p. 403).

\section{Referências bibliográficas}

BOSI, Ecléa. O tempo Vivo da Memória: ensaios de Psicologia Social. São Paulo: Ateliê Editorial, 2003.

CALDAS, Alberto Lins. Oralidade, Texto e História: para ler a história oral. São Paulo, Ed. Loyola, 1999.

CAVALCANTE, Maria Juraci Maia. História e memória da Educação no Ceará. Fortaleza: Imprensa Universitária, 2002.

CAVALCANTE, Maria Juraci Cavalcante e BEZERRA, José Arimatéia Barros. (org.). Biografia, Instituições, Idéias, Experiências e Politicas Educacionais. Fortaleza: Editora UFC, 2003.

CÉSAR, Constança Marcondes (org.) Paul Ricouer: ensaios. São Paulo: Paulus, 1998.

DOSSE, François. A História à Prova do Tempo: da história em migalhas ao resgate do sentido. São Paulo: Editora UNESP, 2001, p. 71-100

A História. Bauru: EDUSC, 2003 (a).

O Império do Sentido: a humanização das ciências humanas. Bauru: EDUSC, 2003 (b).

FERREIRA, Marieta de Moraes e AMADO, Janaína. Usos \& Abusos da História Oral. Rio de Janeiro: Fundação Getúlio Vargas, 1998;

FREITAS, Sônia Maria de. História Oral: possibilidades e procedimentos. São Paulo: Humanitas/Imprensa Oficial do Estado, 2002.

GAGNEBIN, Jeanne Marie. História e Narração em Walter Benjamin. $2^{\mathrm{a}}$ ed. São Paulo: Editora Perspectiva, 1999. 
HAVELOCK, Eric A. A Musa Aprende a Escrever: reflexões sobre a oralidade e a literacia da antiguidade ao presente. Lisboa: Gradiva, 1996.

JUCÁ, Gisafran Nazareno Mota. A Oralidade dos Velhos na Polifonia Urbana. Fortaleza: Imprensa Universitária, 2003.

LEAL, Ivanhoé Albuquerque. História e ação na teoria da narratividade de Paul Ricoeur. Rio de Janeiro: Relume Dumará, 2002.

MAGALHÃES JUNIOR, Antonio Germano. (org. ) História Oral. Fortaleza: LCR, 2001. Colônia. Diálogos Intempestivos.

MENEZES, Eduardo Diatahy Bezerra de. Núcleo de Documentação Cultural - NUDOC. In: HAGUETTE et al. (org. ) Memória das Ciências Sociais na UFC: um exercício de análise institucional. Fortaleza: Edições UFC/Stylus Comunicações, 1991.

MEIHY, José Carlos Sebe Bom. Manual de História Oral. 3ª ed. São Paulo: Ed. Loyola, 2000.

NORA, Pierre. Entre memória e História: a problemática dos lugares. Projeto História, São Paulo, v. 10, dez./1993, p. 7-28.

ONG, Walter. Oralidade e Cultura escrita: a tecnologização da palavra. São Paulo: Papirus, 1998.

RAMALHO, Elba Braga. Cantoria Nordestina: música e palavra. São Paulo: Terceira Margem, 2000 (a).

. Luiz Gonzaga: a síntese poética e musical do sertão. São Paulo, Terceira Margem, 2000 (b).

ROUANET, Sergio Paulo (org.). Walter Benjamin. Obras escolhidas. Vol. 1. São Paulo: Brasiliense, 1985.

ZUMTHOR, Paul. A Letra e a Voz. São Paulo: Companhia das Letras, 1993.

Resumo: Este artigo constitui uma análise das experiências desenvolvidas pelos Grupos de Pesquisa dedicados à História Oral existentes em Fortaleza, nas Universidades Federal do Ceará (UFC) e Estadual do Ceará (UECE). Além do histórico das atividades de pesquisas realizadas, procura-se destacar o alcance da transdisciplinaridade como uma opção metodológica inovadora, e as barreiras que se apresentam, nos grupos mais experientes, à obtenção dos objetivos almejados.

Palavras-chave: oralidade; transdisciplinaridade; história oral; metodologia.

The Northeast and Oral History: the contribution of the Research Groups

Abstract: This paper aims to discuss the research experiences developed by two groups dedicated to Oral History in Fortaleza. These groups belong to the Federal University of Ceará and to the State University of Ceará. Beyond presenting the researches' history, we intend to highlight the revolutionary methodological approach of transdisciplinarity and also the obstacles the most experienced groups have to deal with in order to reach their goals.

Keywords: orality; transdisciplinarity; Oral History; methodology. 